\title{
Volcano spews out hot new catalyst
}

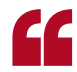

If you assume

all the charge

transfer steps

in the reaction

involve

PCET, then

the thermo-

dynamics of

each step

should be $\mathrm{pH}$

independent

כ5

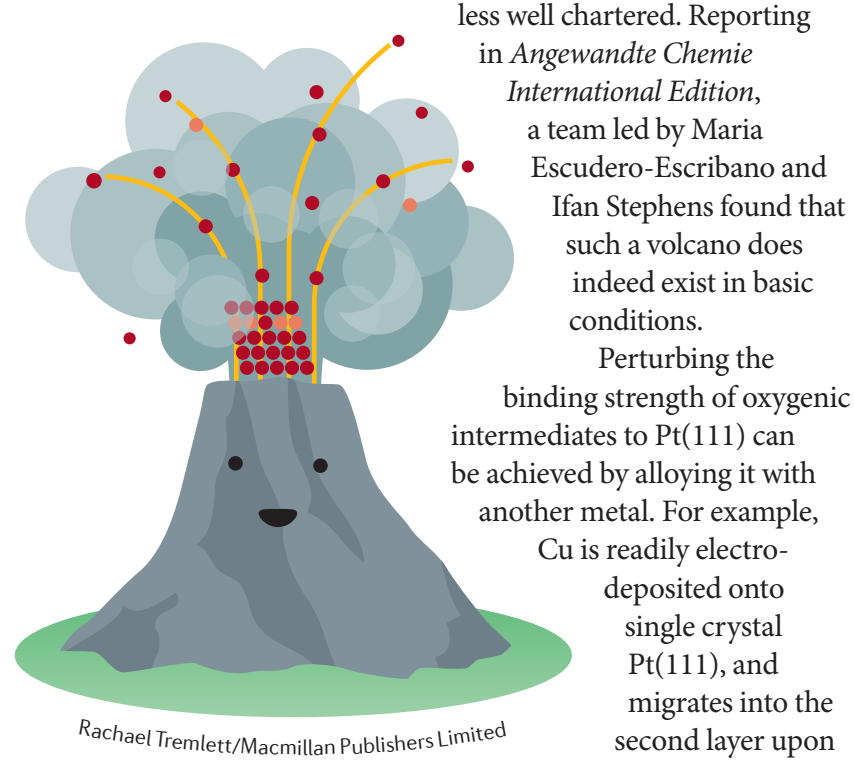

Many fuel cells rely on $4 \mathrm{H}^{+} / 4 \mathrm{e}^{-}$reduction of $\mathrm{O}_{2}$ to $\mathrm{H}_{2} \mathrm{O}$, the individual steps of which may involve proton-coupled electron transfer (PCET). For example, $\mathrm{O}_{2}$ can bind a metal catalyst and be converted into a surface-bound ${ }^{\star} \mathrm{OOH}$ on acceptance of $\mathrm{H}^{+}$and an $\mathrm{e}^{-}$. When PCET is operative, a plot of catalytic activity versus substrate binding strength will be volcano-shaped and have a peak at the optimal binding strength. If the catalyst binds ${ }^{\star} \mathrm{OOH}$ or ${ }^{\star} \mathrm{OH}$ more weakly than the optimum, then these intermediates may form too slowly. Conversely, if binding is too strong then subsequent reactions become too slow. This give-and-take forms the basis of the Sabatier principle, and, with a volcano peak in sight, one can design an active catalyst by adjusting the composition of an alloy to arrive at the sweet spot for binding strength. The volcano is already mapped out for $\mathrm{O}_{2}$ reduction mediated by Pt alloys in acid, but the

reactions in alkaline waters are less well chartered. Reporting Angewandte Chemie ternational Edition, eam led by Maria cudero-Escribano and an Stephens found that such a volcano does indeed exist in basic nditions.

Perturbing the binding strength of oxygenic intermediates to $\mathrm{Pt}(111)$ can e achieved by alloying it with Cu is readiy ectrodeposited onto single crystal migrates into the second layer upon annealing under $\mathrm{H}_{2}$, as confirmed by angle resolved $\mathrm{X}$-ray photoelectron spectroscopy. The $\mathrm{Cu}$ atoms perturb the electronic structure of the $\mathrm{Pt}$ catalytic sites, and cyclic voltammetry of electrodes covered with the alloys in $\mathrm{N}_{2}$-saturated $\mathrm{pH} 13$ solution $(0.1 \mathrm{M}$ $\mathrm{KOH}$ ) show that introducing $\mathrm{Cu}$ increases the potential of a wave at $\sim 0.6 \mathrm{~V}$ associated with the adsorption of ${ }^{\star} \mathrm{OH}$ or ${ }^{\star} \mathrm{O}$ groups. This anodic shift indicates that $\mathrm{Cu}$ destabilizes ${ }^{\star} \mathrm{OH}$ and other intermediates, a result corroborated by density functional theory calculations.

With Pt(111)-Cu alloys of varying composition in hand, the team had materials that could bind ${ }^{\star} \mathrm{OH}$ with a variety of strengths. To identify the optimal strength, the team performed voltammetry on each alloy-covered electrode in the presence of $\mathrm{O}_{2}$, whose transport to the electrode was ensured by rotating the latter at $1600 \mathrm{rpm}$. Comparing the data for the alloys at $0.9 \mathrm{~V}$ versus the reversible hydrogen electrode, the alloy with 0.77 monolayer $\mathrm{Cu}$ emerged as the best catalyst, affording a catalytic current density of $\sim 100 \mathrm{~mA} \mathrm{~cm}^{-2}$. This catalyst binds ${ }^{\star} \mathrm{OH}(0.1 \mathrm{eV})$ more weakly than $\mathrm{Pt}(111)$ does, a shift identical to that observed at $\mathrm{pH}$ 1. "If you assume all the charge transfer steps in the reaction involve PCET, then the thermodynamics of each step should be $\mathrm{pH}$ independent," explain the authors. Thus, PCET is operative not only at low $\mathrm{pH}$ but also at high $\mathrm{pH}$, dispelling any thought of a mechanism involving protondecoupled electron transfer and intermediates such as $\mathrm{O}_{2}^{-}$.

The universality of the $\mathrm{O}_{2}$ reduction mechanism mediated by Pt alloys means we have the design principles to improve on $\mathrm{Pt}-\mathrm{Ni}$ and $\mathrm{Pt}-\mathrm{Co}$ alloys presently used in vehicles. Yet, catalytic rates depend not only on a material's redox potentials and substrate binding strength, but also on variables such as local $\mathrm{pH}$ and stability. Moreover, specific electrolyte-intermediate interactions can also be important, and account for the higher activity of $\mathrm{Pt}(111)-\mathrm{Cu}$ in $\mathrm{KOH}$ solution relative to that in $\mathrm{NaOH}$ solution, as well as the low activity of $\mathrm{Au}(100)$ in acid. EscuderoEscribano, Stephens and co-workers also identified other outliers catalysts that gave data far from the two diagonal lines that define the volcano. For example, stepped Pt surfaces exhibit lower activity than $\mathrm{Pt}(111)$ despite binding ${ }^{\star} \mathrm{OH}$ more weakly. "This suggests that there is an additional barrier to the protonation of these species on stepped surfaces, possibly associated with solvent reorganization," posit the authors. But this gap in our understanding is less important than a key remaining problem: reducing $\mathrm{O}_{2}$ in base means that we need a catalyst to oxidize a fuel such as $\mathrm{H}_{2}$ under similar conditions. Whatever the $\mathrm{pH}$ one chooses to operate at, it is only through systematic studies of cathodic and anodic reactions, as well as development of suitable ion-conducting membranes, that will we develop optimal fuel cell technologies.

David Schilter

ORIGINAL ARTICLE Jensen, K. D. et al.

Elucidation of the oxygen reduction volcano in alkaline media using a copper-platinum(111) alloy. Angew. Chem. Int. Ed. https://doi.org/10.1002/ anie.201711858 (2018)

FURTHER READING Nørskov, J. K. et al. Origin of the overpotential for oxygen reduction at a fuelcell cathode. J. Phys. Chem. B 108, 17886-17892 (2004). 